\title{
LETTER
}

\section{Alpha-2 adrenoceptor agonists and sepsis: improved survival?}

\author{
Luc Quintin* \\ See related research by Pandharipande et al., http://ccforum.com/content/14/2/R38
}

Dr Pandharipande and colleagues should be commended for segregating the effect of dexmedetomidine, an alpha-2 adrenoceptor agonist, in sepsis [1]. However, three questions arise from their study: what are the $P$ values for the data reported in Table 1? Why was there such a discrepancy between the fentanyl dose given to patients on dexmedetomidine and those on lorazepam $(1,114$ versus $117 \mu \mathrm{g} /$ day, $P=0.01)$ considering the 50 to $80 \%$ reduction in the use of opiates commonly observed in the literature when alpha-2 adrenoceptor agonists are administered? And how many days did the patients spend on spontaneous (for example, pressure support) versus controlled/assisted ventilation?

In their study, survival was better (a $70 \%$ reduction in risk of dying at 28 days) in patients on dexmedetomidine $(\mathrm{n}=31)$ than in those on lorazepam $(\mathrm{n}=32)$. Improved survival was observed earlier in tetanus patients [2] (rate of death of $50 \%$ versus $11 \%$ in control $(n=10)$ versus clonidine-treated $(\mathrm{n}=17)$ patients; $P=0.04$; this 1998 reference is not cited in the bibliography). In the study of Dr Pandharipande and colleagues, baseline characteristics were slightly different (Table 1 in [1]): temperature, heart/ respiratory rate, incidence of vasopressors (dexmedetomidine, 32\%; lorazepam, 56\%) and drotrecogin alpha (activated; $P=0.20$ ) were higher and systolic pressure lower in the lorazepam group despite 'similar severity of illness.' Could bias explain partially improved survival? As concluded by the authors [1], a larger trial should demonstrate improved survival (for example, upon septic shock [3]).

Secondly, the dexmedetomidine patients received ten times more fentanyl and had more ventilator-free days. Usually, alpha- 2 adrenoceptor agonists reduce the need for opiates by 50 to $80 \%$ and preserve spontaneous ventilation. So why this discrepancy?

Thirdly, vasopressor requirements were reduced in the dexmedetomidine group (Table 3 in [1]). A 2003 reference [4] showed previously a reduced vasopressor requirement and was not cited in the bibliography. Could more ventilator-free days lead to less infections $[5,6]$, improved survival, lowered intrathoracic pressure and reduced vasopressor requirements?

\section{Authors' response}

Pratik P Pandharipande, Robert D Sanders, Timothy D Girard, Mervyn Maze and E Wesley Ely

Dr Quintin raises interesting questions regarding our analyses of the septic subgroup in the MENDS trial [7], which found improved outcomes and survival in septic patients treated with dexmedetomidine versus lorazepam [1]. In Table 1 , we did not report $P$-values to avoid misleading readers into believing the groups were perfectly balanced. Indeed, we advised caution when interpreting these results since subgroup analyses are

*Correspondence: quintin@univ-lyon1.fr

Physiology (CNRS UMR 5123), University of Lyon, 69622 Lyon-Villeurbanne, France prone to type II errors; that is, due to the reduced sample sizes, some imbalances could have occurred that though not statistically significant - could have been clinically important. We attempted, therefore, to reduce the impact of potential imbalances by adjusting for age, severity of illness and use of drotrecogin alfa.

Fentanyl was used both as an analgesic and supplemental sedative when a deeper level of sedation (than that achieved with the study drug) was ordered by the medical team. Higher doses of fentanyl were noted in the dexmedetomidine group primarily when patients were deeply sedated [7], suggesting the increased fentanyl use reflected a need for additional sedation 
rather than analgesia. Previous studies reporting opioidsparing effects of dexmedetomidine have examined intraoperative use [8] or short-term use after surgery [9], both of which involve different populations than that studied in MENDS.

We did not evaluate modes of ventilation. We did find an increase in ventilator-free days in septic patients sedated with dexmedetomidine versus lorazepam, but did not find a reduction in secondary infections as seen in SEDCOM [6]. Thus, our results do not support the hypothesis that a reduced ventilator time in the septic dexmedetomidine group resulted in lower secondary infections and thereby improved survival.

\section{Competing interests}

PPP, TGD, MME and EWE received research grants and honoraria from Hospira Inc. This is an investigator initiated study and Hospira Inc did not have a role in the generation of the hypothesis, conduct of the trial, data analysis or financing of the manuscript.

PPP and EWE received honoraria from GSK; EWE received honoraria from Aspect Medical and Eli Lily. None of these have any relevance to this manuscript.

\section{Acknowledgements}

LQ received grants and honoraria from Bohringer-Ingelheim France, UCB Pharma-Belgium, Abbott International (1986-95).

Published: 29 July 2010

\section{References}

1. Pandharipande PP, Sanders RD, Girard TD, McGrane S, Thompson JL, Shintani AK, Herr DL, Maze M, Ely EW, Mends IT: Effect of dexmedetomidine versus lorazepam on outcome in patients with sepsis: an a priori-designed analysis of the MENDS randomized controlled trial. Crit Care 2010, 14:R38.

2. Gregorakos L, Kerezoudi E, Dimopoulos G, Thomaides T: Management of blood pressure instability in severe tetanus: the use of clonidine. Intensive Care Med 1997, 23:893-895.

3. Pichot C, Mathern P, Khettab F, Ghignone M, Geloen A, Quintin L: Increased pressor response to noradrenaline during septic shock following clonidine? Anesthesia Intensive Care (Sydney) 2010, in press.

4. Venn RM, Newman PJ, Grounds RM: A phase II study to evaluate the efficacy of dexmedetomidine for sedation in the medical intensive care unit. Int
Care Med 2003, 29:201-207.

5. Spies CD, Dubisz N, Neumann T, Blum S, Muller C, Rommelspacher $H$, Brummer G, Specht M, Sanft C, Hannemann L, Striebel HW, Schaffartzik W: Therapy of alcohol withdrawal syndrome in intensive care unit patients following trauma: results of a prospective, randomized trial. Crit Care Med 1996, 24:414-422.

6. Riker RR, Shehabi Y, Bokesch PM, Ceraso D, Wisemandle W, Koura F, Whitten P, Margolis BD, Byrne DW, Ely EW, Rocha MG: Dexmedetomidine vs midazolam for sedation of critically ill patients: a randomized trial. JAMA 2009, 301:489-499.

7. Pandharipande PP, Pun BT, Herr DL, Maze M, Girard TD, Miller RR, Shintani AK, Thompson JL, Jackson JC, Deppen SA, Stiles RA, Dittus RS, Bernard GR, Ely EW: Effect of sedation with dexmedetomidine vs lorazepam on acute brain dysfunction in mechanically ventilated patients: the MENDS randomized controlled trial. JAMA 2007, 298:2644-2653.

8. Arain SR, Ruehlow RM, Uhrich TD, Ebert TJ: The efficacy of dexmedetomidine versus morphine for postoperative analgesia after major inpatient surgery. Anesth Analg 2004, 98:153-158.

9. Venn RM, Grounds RM: Comparison between dexmedetomidine and propofol for sedation in the intensive care unit: patient and clinician perceptions. Br J Anaesth 2001, 87:684-690.

doi:10.1186/cc9096

Cite this article as: Quintin L: Alpha-2 adrenoceptor agonists and sepsis: improved survival? Critical Care 2010, 14:429. 